\title{
Evaluation of Sample Preparation Techniques for Mass Measurements of PCR Products using ESI-FT-ICR Mass Spectrometry
}

\author{
Allison P. Null, Laura T. George, and David C. Muddiman ${ }^{*,+}$ \\ Department of Chemistry, Virginia Commonwealth University, Richmond, Virginia, USA
}

\begin{abstract}
Elimination of PCR buffer components and alkali metal cations (i.e., $\mathrm{Na}^{+}, \mathrm{K}^{+}$) is of critical importance to allow for accurate mass measurements of PCR products for genotyping and sequencing applications. Ethanol precipitation followed by microdialysis has been repeatedly shown to efficiently desalt PCR products for analysis by mass spectrometry and is considered the gold standard. Alternative cleanup techniques that are compatible with automation are explored here with the intent of expanding the bottleneck that exists between the production of PCR products and analysis by electrospray ionization mass spectrometry (ESI-MS). Numerous combinations of approaches were evaluated that included PCR purification kits and alcohol precipitations. The data shown here support alternative approaches to an ethanol precipitation followed by microdialysis that have comparable desalting efficiency and can be utilized for cleanup of PCR products generated from single reactions. (J Am Soc Mass Spectrom 2002, 13, 338-344) (C) 2002 American Society for Mass Spectrometry
\end{abstract}

$\mathrm{A}$ high propensity for the adduction of cations (i.e., $\mathrm{Na}^{+}, \mathrm{K}^{+}$) to the negatively charged phosphate backbone of nucleic acids warrants an efficient desalting technique for their characterization by electrospray ionization mass spectrometry (ESI-MS) [1]. Additionally, analysis of polymerase chain reaction (PCR) [2] products for genotyping requires efficient removal of PCR reaction components such as DNA polymerase, as well as excess primers and deoxynucleotide triphosphates (dNTPs) [3, 4]. This necessity presents a challenge to mass spectrometrists since the cleanup approach chosen should ideally be rapid, as well as efficient. Currently, thermal cyclers have a capacity of four 96-well plates; thus, generation of 386 different PCR products in parallel is possible. While mass spectrometric analysis of DNA is inherently serial in nature, the use of flow-injection coupled with Fourier transform ion cyclotron resonance mass spectrometry (FT-ICR-MS) [5] has demonstrated that more than 300 samples can be analyzed per day [6] while the use of an automated liquid handing system increases throughput to greater than 1700 samples per day [7]! However, a bottleneck exists between PCR and mass spectrometric analysis because of the time currently required for sample cleanup, greatly limiting the number of PCR

Published online February 13, 2002

Address reprint requests to Dr. D. C. Muddiman, Department of Chemistry, Virginia Commonwealth University, 1001 West Main Street, Richmond, VA 23284, USA. E-mail: dcmuddim@mail1.vcu.edu

*Affiliate Appointment in Biochemistry and Molecular Biophysics.

${ }^{+}$The Massey Cancer Center. products that can be analyzed and therefore, the number of genotypes obtained per day.

Numerous techniques have been utilized for the preparation of oligonucleotides and PCR products for mass spectrometry including immobilization by biotin/ streptavidin chemistry [8-10], phenol/chloroform extractions [11, 12], size-exclusion filters [8, 12-14], silica resin [10], cation-exchange resin beads [15], anionexchange HPLC [15], $C_{18}$ purification pipet tips [15], desalting columns [15], minidialysis [15], gel filtration [16], magnetic particles [14], ethanol precipitation [10, 11, 14, 16-18], and microdialysis [19-21]. The coupling of an ethanol precipitation and microdialysis, first demonstrated by our group [22], has been shown to efficiently desalt PCR products for analysis by mass spectrometry [4, 6, 22-28]. Ethanol precipitation removes dNTPs, primers and enzyme present in the PCR reaction whereas microdialysis eliminates nonvolatile cations by ion exchange (i.e., with the volatile cation $\mathrm{NH}_{4}^{+}$) with an efficiency of greater than $99.9 \%$ for $\mathrm{Mg}^{2+}$ [22]. However, microdialysis is undesirable in that it is time-consuming and not amenable to automation. The goal of this work was to evaluate alternative techniques that have a high desalting efficiency for purifying PCR products, enabling their rapid characterization by ESIFT-ICR-MS.

The cleanup strategies examined fall into two categories: (1) PCR purification kits-the commercially available GENECLEAN and Genopure ${ }_{\mathrm{ds}}$ kits were evaluated, both of which immobilize DNA within a membrane (GENECLEAN) or on coated magnetic beads $\left(\right.$ Genopure $\left._{\mathrm{ds}}\right)$, allowing several washes to purify PCR 
Table 1. Summary of PCR product cleanup appoaches

\begin{tabular}{|c|c|c|c|c|c|}
\hline Approach & Technique 1 & Technique 2 & Technique 3 & Results $^{a}$ & Hands-on time (min) \\
\hline \multicolumn{6}{|l|}{ Kits } \\
\hline 1 & Geneclean & Ethanol precipitation & & $\checkmark$ & 7 \\
\hline 2 & Geneclean & Ethanol precipitation & Microdialysis & $\checkmark$ & 36 \\
\hline 3 & Genopure & Ethanol precipitation & Microdialysis & $\checkmark$ & 62 \\
\hline 4 & Genopure & & & $x$ & 30 \\
\hline \multicolumn{6}{|c|}{ Precipitations } \\
\hline 5 & Ethanol precipitation & Ethanol precipitation & & $\checkmark$ & 6 \\
\hline 6 & Isopropanol precipitation & Ethanol precipitation & & $\checkmark$ & 6 \\
\hline 7 & Ethanol precipitation & Microdialysis & & $\checkmark$ & 32 \\
\hline 8 & Ethanol precipitation & & & $x$ & 3 \\
\hline 9 & Isopropanol precipitation & & & $x$ & 3 \\
\hline
\end{tabular}

${ }^{\mathrm{a}} \boldsymbol{X}=$ mass spectra resulted in either an extremely salty PCR product or no peaks observed after numerous attempts. $\checkmark=$ mass spectra resulted in a well-desalted PCR product.

products from primers and dNTPs prior to elution and (2) alcohol precipitations-alcohol (i.e., ethanol, isopropanol) is widely used in biological applications to precipitate DNA in the presence of a high concentration of salt (ca. $1 \mathrm{M})$. Alcohol precipitations are intended to eliminate primers, enzymes, dNTPs, and salts present in solution while concentrating DNA [29]. Extensive evaluation of these techniques was performed in multiple combinations to investigate an approach that will allow efficient, rapid, and eventually automatable cleanup of PCR products enabling their rapid characterization by ESI FT-ICR mass spectrometry.

\section{Experimental}

\section{PCR Amplification}

The tetranucleotide repeat region within exon 1 of the human tyrosine hydroxylase gene (HUMTH01) (GenBank accession: D00269) and exon 40 of the von Willebrand factor gene (vWA) (GenBank accession: M25858) were separately amplified from K562 human genomic DNA (Promega, Madison, WI) by PCR. Each $50 \mu \mathrm{L}$ reaction contained $1 \times$ cloned Pfu buffer $(20 \mathrm{mM}$ Tris$\mathrm{HCl}(\mathrm{pH} 8.8), 2 \mathrm{mM} \mathrm{MgSO}, 10 \mathrm{mM} \mathrm{KCl}, 10 \mathrm{mM}$ $\left(\mathrm{NH}_{4}\right)_{2} \mathrm{SO}_{4}, 0.1 \%$ Triton X-100, $0.1 \mathrm{mg} / \mathrm{mL}$ BSA) (Stratagene, La Jolla, CA), 1.25 U PfuTurbo DNA polymerase (Stratagene), $0.2 \mathrm{mM}$ dNTPs (Perkin-Elmer, Branchburg, NJ), 25 pmol (HUMTH01) or 12.5 pmol (vWA) primer, and 100 ng of DNA template. All PCR products were prepared in our laboratory with a 96-well MJ Research PTC-200 Thermal Cycler (Watertown, MA) using previously described PCR parameters and primers [28]. The individual from whom the genomic DNA was obtained is homozygous for allele 9.3 at the HUMTH01 locus and homozygous for allele 18 at the vWA locus. The double-stranded PCR product generated from the HUMTH01 locus is 82 base-pairs with an average molecular weight of $50,535 \mathrm{Da}$, whereas the double-stranded PCR product generated from the vWA locus is 116 base-pairs with an average molecular weight of 71,533 Da.

\section{PCR Product Purification and Desalting}

Table 1 summarizes the combinations of approaches that were evaluated, including the hands-on time for each cleanup method. The protocol for each approach is described in detail below.

GENECLEAN. The procedure that accompanied the GENECLEAN kit (Q.BIOgene, Carlsbad, CA) was adhered to as follows: A single $50 \mu \mathrm{L}$ PCR reaction was combined with 5 volumes of GENECLEAN Turbo salt solution and mixed well. The solution was then transferred to a GENECLEAN Turbo cartridge containing the binding matrix within a filter, and was centrifuged for 5 s. $500 \mu \mathrm{L}$ of ethanol (200 proof) was added to the filter and the cartridge centrifuged for $5 \mathrm{~s}$. The wash step was repeated followed by a 4 min centrifugation step. The cartridge was transferred to $1.5 \mathrm{~mL}$ GENECLEAN Turbo catch tube. $30 \mu \mathrm{L}$ of elution solution was added and allowed to incubate for $5 \mathrm{~min}$. The PCR product was collected in the catch tube by centrifuging for $30 \mathrm{~s}$. The elution step was repeated once more to maximize recovery.

Genopure $_{d s}$. The protocol included with the Genopure $_{\mathrm{ds}}$ kit (Bruker Daltonics, Billerica, MA) was followed as described: $40 \mu \mathrm{L}$ of a PCR reaction was mixed with $5 \mu \mathrm{L}$ of magnetic beads and $50 \mu \mathrm{L}$ of binding buffer. The bound PCR product was washed 5 times with an isopropanol-based buffer for highest purity of PCR product and twice with an ethanol-based buffer. Washing was accomplished by moving the PCR tube back and forth in a 96-well magnetic separation device. The PCR product was eluted in $10 \mu \mathrm{L}$ of water. This approach has recently been shown for PCR products using ESI ion trap mass spectrometry [14].

Ethanol precipitation. Precipitations were performed as outlined by Crouse and Amorese [30], which have been previously reported for ESI-MS [17, 18]. 0.5 volumes of 7.5 $\mathrm{M}$ ammonium acetate were added to 1-4 PCR reactions and mixed well. 2.5 volumes of $100 \%$ ethanol 
were added and mixed by flipping the tube end over end. After an overnight incubation at $4{ }^{\circ} \mathrm{C}$, the precipitated product was collected by centrifuging at $16,000 \times$ $g$ for $30 \mathrm{~min}$. The pellet was rinsed with $200 \mu \mathrm{L}$ of cold $70 \%$ ethanol to remove excess salt and lyophilized until dry.

Isopropanol precipitation. 0.5 volumes of $7.5 \mathrm{M}$ ammonium acetate were added to a single $50 \mu \mathrm{L}$ PCR reaction followed by 0.7 volumes of room temperature isopropanol [31]. After mixing well, the solution was centrifuged at $16,000 \times g$ for $15 \mathrm{~min}$. After discarding the supernatant, the precipitated DNA was washed with 1 $\mathrm{mL}$ of $70 \%$ ethanol to eliminate excess salt and to replace the isopropanol with the more volatile ethanol. The PCR product was collected by another centrifugation step for $5 \mathrm{~min}$.

Microdialysis Microdialysis was performed using the original design of Liu et al. [19] and has been previously demonstrated for PCR products using ESI-FT-ICR mass spectrometry $[4,6,22,24-28,32]$.

\section{Mass Spectrometry}

All mass spectra were obtained using an IonSpec (Irvine, CA, USA) 4.7 tesla Fourier transform ion cyclotron resonance (FT-ICR) mass spectrometer, which has been previously described elsewhere [33]. The electrospray ionization source (Analytica of Branford, Branford, CT) was modified to accept a heated metal capillary [34] and a dual electrospray source $[26,35]$ for introduction of an internal standard. All PCR products were electrosprayed using a flowrate of $200 \mathrm{~nL} / \mathrm{min}$ from a solution consisting of $60 \%$ acetonitrile, $20 \%$ isopropanol, $20 \mathrm{mM}$ piperidine, $20 \mathrm{mM}$ imidazole [36, 37], and $2 \mathrm{mM}$ ammonium acetate. Poly(ethylene glycol) $(\mathrm{MW}=2000)$ (Sigma) was used as an internal standard when necessary. Mass spectra were generated using $32 \mathrm{k}$ points of data at an ADC rate of $500 \mathrm{kHz}$ and Fourier transformed following 2 zero fills.

\section{Results and Discussion}

The anionic phosphate backbone of nucleic acids is highly susceptible to the electrostatic binding of cations in solution. The PCR product encounters cations that are contributed by the reaction buffer $\left(\mathrm{H}^{+}, \mathrm{K}^{+}, \mathrm{Mg}^{2+}\right.$, $\left.\mathrm{NH}_{4}^{+}\right)$, the ESI solution $\left(\mathrm{H}^{+}, \mathrm{NH}_{4}^{+}\right.$, piperidine $\left.\left[\mathrm{C}_{5} \mathrm{H}_{12} \mathrm{~N}\right]^{+}\right)$, and the ubiquitous $\mathrm{Na}^{+}$. Although the mechanism is not completely understood, a neutral loss of $\mathrm{C}_{5} \mathrm{H}_{11} \mathrm{~N}$ and $\mathrm{NH}_{3}$ in the gas phase leaves DNA protonated [37]. Electrostatic binding of nonvolatile cations to the phosphate backbone, specifically $\mathrm{Na}^{+}$and $\mathrm{K}^{+}$, increases the mass of the observed product, resulting in additional peaks observed in the mass spectra and an overall reduction in signal intensity. In a previous publication, we reported on the use of ICP-AES to measure the amount of $\mathrm{Mg}^{2+}$ present after microdialy- sis. These data showed that microdialysis eliminated $99.9 \%$ of the $\mathrm{Mg}^{2+}$ although adducts were still observed in the mass spectrum [23]. We are currently developing an approach based upon probability theory to estimate the concentration of nonvolatile cations in solution [7]. This approach will take into account the relative binding affinities of the countercations for the phosphate backbone and the relative peak intensities in the mass spectra. The intent of this report is to compare the mass spectra generated from PCR products to determine the relative amounts of alkali metal adduction that result from various cleanup techniques.

To date, the most effective strategy for purification and desalting of PCR products has been a single ethanol precipitation followed by microdialysis $[4,6,22,24-28$, 32]. Figure 1a shows an ESI-FT-ICR mass spectrum of the double-stranded 82-base pair PCR product derived from the HUMTH01 locus in which four reactions were pooled then prepared for mass spectrometric analysis using ethanol precipitation followed by microdialysis. The result is a high quality mass spectrum suitable for genotyping. The average mass for the PCR product was determined using the most intense peak at each charge state and calibrated using PEG (MW = 2000) as an internal standard (internally calibrated mass spectra are not shown to avoid confusion). The internally calibrated experimental average mass was $50,536.61 \mathrm{Da} \pm 0.96 \mathrm{Da}$ $(N=7)$, which corresponds to a mass accuracy of 22.6 ppm $\pm 18.9 \mathrm{ppm}$. This accuracy implies that the most abundant species in the gas phase is that of the PCR product with zero alkali metal cations adducted to the backbone. Adduction of $\mathrm{Na}^{+}$, for example, would create mass errors that exceed $400 \mathrm{ppm}$. An expansion of the $23^{-}$charge state is shown in Figure 1a to illustrate the peak shape and the presence of low intensity peaks due to $\mathrm{Na}^{+}$and $\mathrm{K}^{+}$adduction.

Clearly, an ethanol precipitation followed by microdialysis is efficient for desalting; however, microdialysis can be time-consuming and is not practical for high throughput applications. For this reason, an evaluation of alternative cleanup procedures was performed using combinations of purification kits and alcohol precipitations. The goal was to find a rapid and efficient approach that is compatible with automation, thus eliminating most of the hands-on time for sample preparation. Table 1 shows the various combinations of PCR product cleanup techniques examined in this study with each approach utilizing from one to three steps. An $x$ indicates that the mass spectrum of the PCR product resulted in either an extremely salty PCR product or no peaks observed after numerous attempts. A check signifies those techniques that resulted in a well-desalted PCR product that is suitable for genotyping. Recall that Approach 7 is considered the gold standard and the data were shown in Figure 1a.

The PCR purification kit Genopure ${ }_{\mathrm{ds}}$ proved unsuccessful in multiple attempts and variations. Figure 2a shows a mass spectrum of the 116 base pair PCR product derived from the vWA locus after purification 

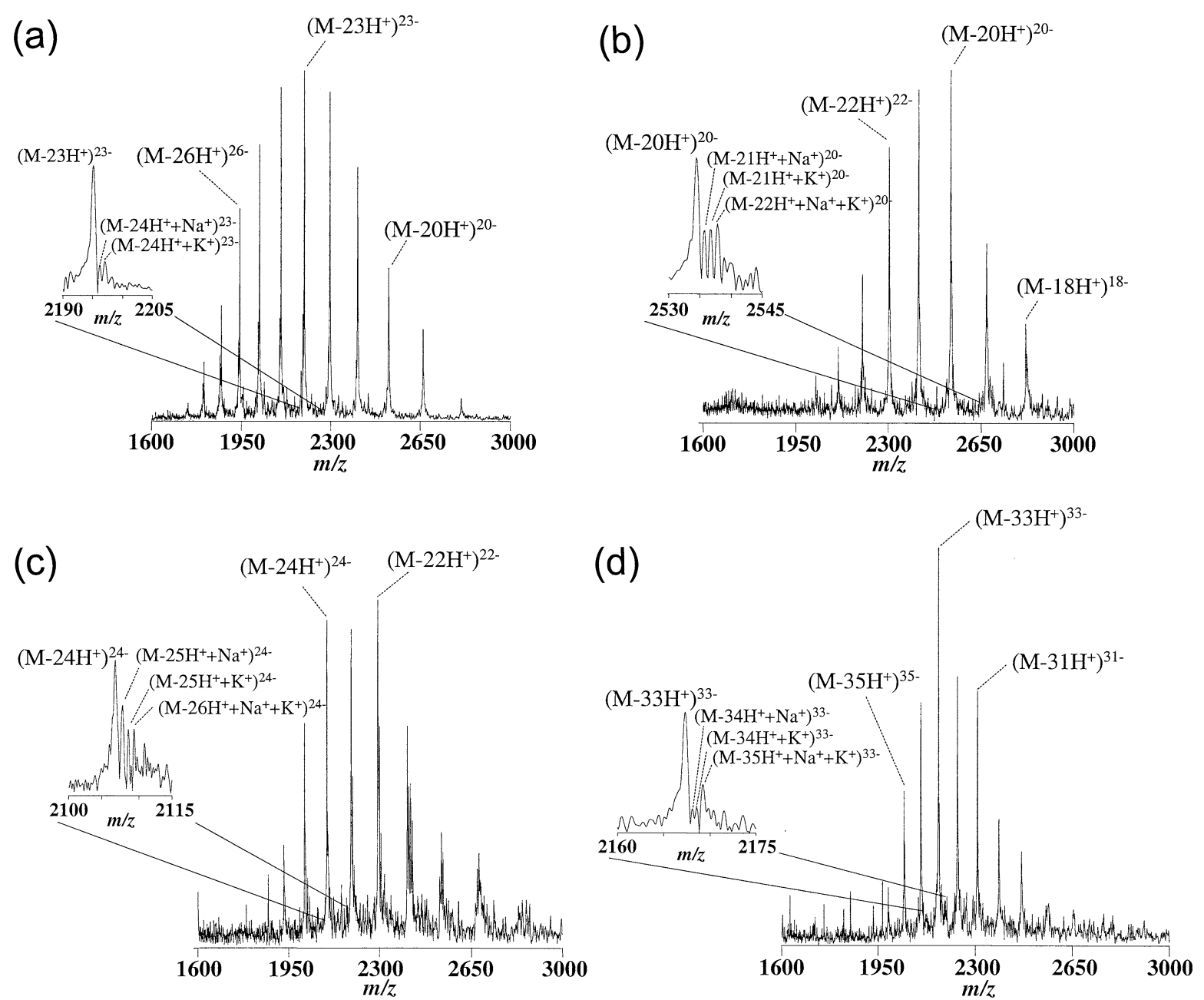

Figure 1. Single-acquisition ESI-FT-ICR mass spectra of double-stranded PCR products that were prepared by various cleanup approaches and expansion spectra of single charge states to demonstrate the desalting efficiency. (a) A PCR product derived from the HUMTH01 locus prepared by ethanol precipitation followed by microdialysis. (b) A PCR product generated from a single $50 \mu \mathrm{L}$ PCR reaction and derived from the HUMTH01 locus following GENECLEAN purification and an ethanol precipitation. (c) Four pooled $50 \mu \mathrm{L}$ reactions of PCR products derived from the HUMTH01 locus after two consecutive ethanol precipitations. (d) A PCR product generated from a single $50 \mu \mathrm{L}$ reaction, and derived from the vWA locus, after sequential isopropanol and ethanol precipitations.

using the magnetic beads. Only polymer was observed in this spectrum with units differing by $44 \mathrm{Da}$, which is attributed to detergent such as Triton X-100 that is used in PCR. Figure $2 \mathrm{~b}$ shows a mass spectrum in which the same double-stranded PCR product was further purified using an ethanol precipitation and microdialysis. A good quality spectrum was obtained for the doublestranded product including a small amount of the coding strand; the noncoding strand was not observed in the mass spectrum. This result indicates that the PCR product is not being lost during cleanup, but that the magnetic beads are not efficient enough to observe a PCR product in the mass spectrum. This result is inconsistent with a previous report using Genopure $\mathrm{ds}_{\mathrm{ds}}$ [14].

Figure $1 \mathrm{~b}$ shows a single-acquisition ESI-FT-ICR mass spectrum of the single-reaction, double-stranded
PCR product derived from the HUMTH01 locus using GENECLEAN followed by an ethanol precipitation. The expansion spectrum indicates that $\mathrm{Na}^{+}$and $\mathrm{K}^{+}$ adducts are observed. Based on internally calibrated mass measurements, the experimental average mass is $50,533.66 \mathrm{Da} \pm 0.89 \mathrm{Da}$ reported as the $95 \%$ confidence interval of the mean $(N=21)$, which corresponds to a mass error of $-35.0 \mathrm{ppm} \pm 18.5 \mathrm{ppm}$. Clearly, the most abundant species in the mass spectrum is that of the PCR product with only $\mathrm{H}^{+}$as a countercation. As shown in Table 1, GENECLEAN requires only 4 min of hands-on time and can be completed without an overnight incubation step. The eluent from the GENECLEAN step is immediately ethanol precipitated, which requires 3 min of hands-on time followed by an overnight incubation step to maximize yield.

Another successful approach elucidated in this study 


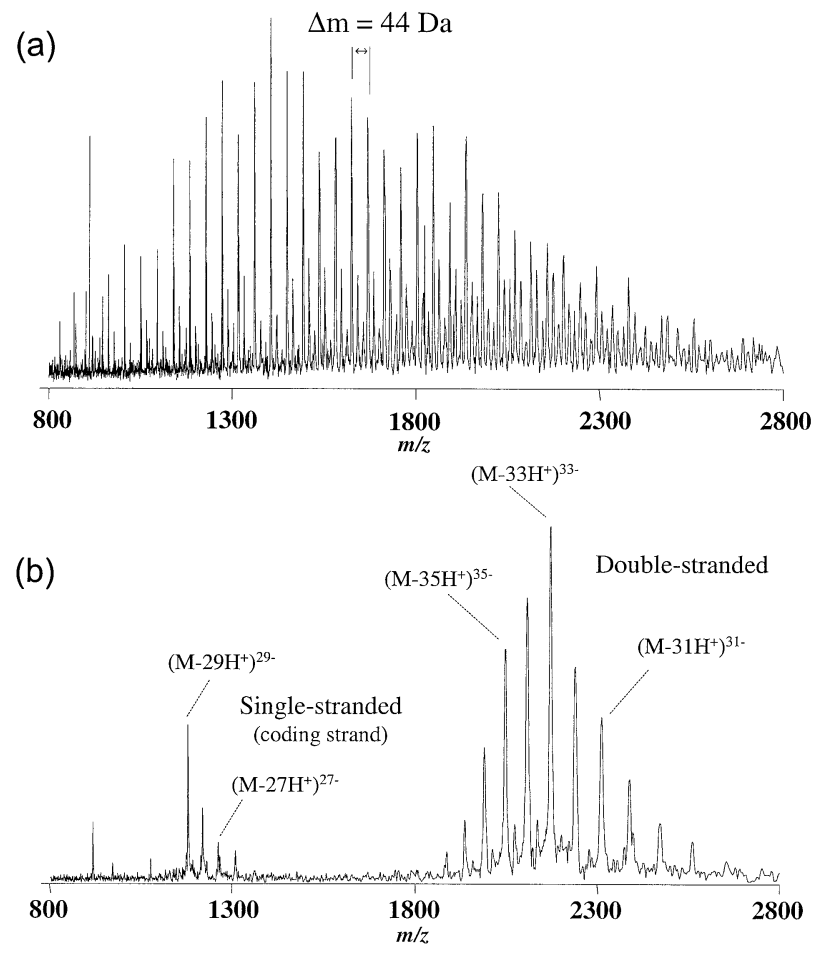

Figure 2. ESI-FT-ICR mass spectra of the PCR product derived from the vWA locus after purification using (a) Genopure ds $_{\text {s }}$ and

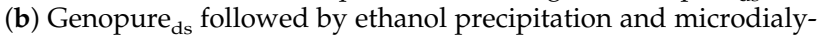
sis. The mass spectra were derived from the same set of reactions and purified simultaneously. The spacing between polymer peaks in (a) is $44 \mathrm{Da}$. This spacing could be due to a detergent such as Triton $\mathrm{X}-100$. The spectrum in (b) shows the single stranded $(\mathrm{m} / \mathrm{z}$ $1100-1300)$ and double stranded $(m / z$ 1800-2800) PCR products derived from the vWA locus. Only the coding single-stranded form was observed at a significant amount in this spectrum.

was the use of a double ethanol precipitation. Figure 1c shows a single-acquisition ESI-FT-ICR mass spectrum of four pooled reactions derived from the HUMTH01 locus after a double ethanol precipitation. The experimental average mass was $50,535.59 \mathrm{Da} \pm 0.89 \mathrm{Da}$ reported as the $95 \%$ confidence interval of the mean $(N=35)$, which corresponds to a mass error of $2.3 \mathrm{ppm}$ $\pm 17.6 \mathrm{ppm}$. Although the most intense peaks in the spectrum represent the species of PCR product that do not have alkali metal countercations, the expansion of the $24^{-}$charge state reveals that there are multiple species with $\mathrm{Na}^{+}$and $\mathrm{K}^{+}$adducts. Since the peaks due to alkali metal adduction were resolved, the average molecular mass was not affected; however, the distribution of ion intensity over multiple peaks does reduce the overall signal-to-noise. Double ethanol precipitations require only $6 \mathrm{~min}$ of hands-on time (see Table 1); however, they require two consecutive overnight incubations.

A double alcohol precipitation using isopropanol followed by ethanol also proved to be an effective approach to purification and desalting. Figure $1 \mathrm{~d}$ shows a single acquisition ESI-FT-ICR mass spectrum of the double-stranded, single-reaction PCR product derived from the vWA locus after the isopropanol and ethanol double precipitations. An internal standard was not included for this single reaction PCR product; however, internally calibrated mass measurements obtained for the HUMTH01 locus (data not shown) resulted in an average mass of $50,535.88 \mathrm{Da} \pm 1.79 \mathrm{Da}$ reported as the $95 \%$ confidence interval of the mean $(N=28)$, which corresponds to a mass error of $8.1 \mathrm{ppm} \pm 35.5 \mathrm{ppm}$. This confirms that the most intense peaks are that of the PCR product where the phosphate groups are neutralized by protons. A typical peak is shown in the expansion plot of the $33^{-}$charge state for the vWA locus illustrating some $\mathrm{Na}^{+}$and $\mathrm{K}^{+}$adduction. Like the double ethanol precipitation, the double precipitation with isopropanol followed by ethanol requires only 6 min of hands-on time (see Table 1) with the added advantage of requiring only a single overnight incubation.

As a result of these data, three alternatives to ethanol precipitation followed by microdialysis were elucidated; namely, GENECLEAN followed by an ethanol precipitation, tandem ethanol precipitations, and an isopropanol followed by an ethanol precipitation. Each was found to be reproducible after numerous trials with only slight variations in desalting efficiency. Furthermore, we have shown that good quality mass spectra are obtained from purification of single PCR reactions, which allows for purification and analysis using a 96-well format. The techniques described here require a shorter hands-on time (Table 1) than ethanol precipitation followed by microdialysis, and with automation, the hands-on time will be greatly reduced (i.e., robotics). Overnight incubations are required for ethanol precipitations; however, overnight time constraints are meaningless when numerous samples are analyzed in a high-throughput laboratory.

\section{Conclusions}

It is important that a desalting approach for PCR products be rapid as well as efficient to allow high throughput analysis by mass spectrometry. The three approaches elucidated in this study offer the best alternatives to an ethanol precipitation followed by microdialysis since they reduce alkali metal concentrations to comparable levels for characterization of PCR products by ESI mass spectrometry. We are currently developing an approach for measuring the concentration of nonvolatile countercations to compare the relative efficiency of desalting for various techniques. Since each approach described here is amenable to automation in a 96-well format, they will likely expand the bottleneck existing because of sample cleanup in ESI mass spectrometric analysis of PCR products with potential for maximizing throughput.

\section{Acknowledgments}

The authors thank Dr. James C. Hannis for his assistance with some of the experiments. The authors gratefully acknowledge the 
National Institutes of Health (R01HG02159), the David F. Ingraham Scholarship Fund (LTG) and the Department of Chemistry (Mary E. Kapp Foundation), Virginia Commonwealth University, for their generous financial support.

\section{References}

1. Fenn, J. B.; Mann, M.; Meng, C. K.; Wong, S. F.; Whitehouse, C. M. Electrospray Ionization for Mass Spectrometry of Large Biomolecules. Science 1989, 246, 64-71.

2. Mullis, K.; Faloona, F. Specific Synthesis of DNA in vitro via a Polymerase-Catalyzed Chain Reaction. Methods Enzymol. 1987, 155, 335.

3. Muddiman, D. C.; Smith, R. D. Sequencing and Characterization of Larger Oligonucleotides by Electrospray Ionization Fourier Transform Ion Cyclotron Resonance Mass Spectrometry. Rev. Anal. Chem. 1998, 17, 1-68.

4. Null, A. P.; Muddiman, D. C. Perspectives on the Use of Electrospray Ionization Fourier Transform Ion Cyclotron Resonance Mass Spectrometry for Short Tandem Repeat Genotyping in the Post-Genome Era. J. Mass Spectrom. 2001, 36, 589-606.

5. Comisarow, M. B.; Marshall, A. G. Fourier Transform Ion Cyclotron Resonance Mass Spectrometry. Chem. Phys. Lett. 1974, 25, 282-283.

6. Hannis, J. C.; Muddiman, D. C. Genotyping Short Tandem Repeats Using Flow Injection and ESI FT-ICR-MS. Rapid. Commun. Mass Spectrom. 2001, 15, 348-350.

7. George, L. T.; Null, A. P.; Hannis, J. C.; Muddiman, D. C. Extensive Evaluation of Novel Sample Preparation Techniques for High Sensitivity Mass Measurements of Nucleic Acids Using ESI-FTICR-MS. Proceedings of the American Society of Mass Spectrometry and Allied Topics; Chicago, Illinois, May 2001; 49, ThPK266.

8. Ross, P. L.; Belgrader, P. Analysis of Short Tandem Repeat Polymorphisms in Human DNA by Matrix-Assisted Laser Desorption/Ionization Mass Spectrometry. Anal. Chem. 1997, 69, 3966-3972.

9. Fei, Z.; Ono, T.; Smith, L. MALDI-TOF Mass Spectrometric Typing of Single Nucleotide Polymorphisms with MassTagged ddNTPs. Nucleic Acids Res. 1998, 26, 2827-2828.

10. Krahmer, M. T.; Johnson, Y. A.; Walters, J. J.; Fox, K. F.; Fox, A. F.; Nagpal, M. Electrospray Quadrupole Mass Spectrometry Analysis of Model Oligonucleotides and Polymerase Chain Reaction Products: Determination of Base Substitutions, Nucleotide Additions/Deletions, and Chemical Modifications. Anal. Chem. 1999, 71, 2893-2900.

11. Naito, Y.; Ishikawa, K.; Koga, Y.; Tsuneyoshi, T.; Terunuma, H. Molecular Mass Measurement of Polymerase Chain Reaction Products Amplified from Human Blood DNA by Electrospray Ionization Mass Spectrometry. Rapid Commun. Mass Spectrom. 1995, 9, 1484-1486.

12. Ono, T.; Scalf, M.; Smith, L. M. 2'-Fluoro Modified Nucleic Acids: Polymerase-Directed Synthesis, Properties, and Stability to Analysis by Matrix-Assisted Laser Desorption/ Ionization Mass Spectrometry. Nucleic Acids Res. 1997, 25, $4581-4588$.

13. Wunschel, D. S.; Fox, K. F.; Fox, A.; Bruce, J. E.; Muddiman, D. C.; Smith, R. D. Analysis of Double-Stranded Polymerase Chain Reaction Products from the Bacillus cereus Group by Electrospray Ionization Fourier Transform Ion Cyclotron Resonance Mass Spectrometry. Rapid Commun. Mass Spectrom. 1996, 10, 29-35.

14. Hahner, S.; Schneider, A.; Ingendoh, A.; Mosner, J. Analysis of Short Tandem Repeat Polymorphisms by Electrospray Ion Trap Mass Spectrometry. Nucleic Acids Res. 2000, 28, e82.
15. Ragas, J. A.; Simmons, T. A.; Limbach, P. A. A Comparative Study on Methods of Optimal Sample Preparation for the Analysis of Oligonucleotides by Matrix-Assisted Laser Desorption/Ionization Mass Spectrometry. Analyst (Special Issue: Biological Mass Spectrometry) 2000, 125, 575-581.

16. Taranenko, N. I.; Golovlev, V. V.; Allman, S. L.; Taranenko, N. V.; Chen, C. H.; Hong, J.; Chang, L. Y. Matrix-Assisted Laser Desorption/Ionization for Short Tandem Repeat Loci. Rapid Commun. Mass Spectrom. 1998, 12, 413-418.

17. Stults, J. T.; Marsters, J. C. Improved Electrospray Ionization of Synthetic Oligodeoxynucleotides. Rapid Commun. Mass Spectrom. 1991, 5, 359-363.

18. Limbach, P. A.; Crain, P. F.; McCloskey, J. A. Molecular Mass Measurement of Intact Ribonucleic Acids Via Electrospray Ionization Quadrupole Mass Spectrometry. J. Am. Soc. Mass Spectrom. 1995, 6, 27-39.

19. Liu, C. L.; Wu, Q. Y.; Harms, A. C.; Smith, R. D. On-line Microdialysis Sample Cleanup for Electrospray Ionization Mass-Spectrometry of Nucleic Acid Samples. Anal. Chem. 1996, 68, 3295-3299.

20. Liu, C.; Muddiman, D. C.; Smith, R. D. Improving the Microdialysis Procedure for Electrospray Ionization Mass Spectrometry of Biological Samples. J. Mass Spectrom. 1997, 32, 425431.

21. Wunschel, D. S.; Muddiman, D. C.; Fox, K.; Fox, A.; Smith, R. D. Observation of Inter-Operon Variability Suspected in Normal PCR Using ESI-FTICR Mass Spectrometry. Anal. Chem. 1997, 70, 1203-1207.

22. Hannis, J. C.; Muddiman, D. C. Accurate Characterization of the Tyrosine Hydroxylase Forensic Allele 9.3 Through Development of Electrospray Ionization Fourier Transform Ion Cyclotron Resonance Mass Spectrometry. Rapid Commun. Mass Spectrom. 1999, 13, 954.

23. Hannis, J. C.; Muddiman, D. C. Characterization of a Microdialysis Approach for the Preparation of PCR Products for ESI-MS Using ICP-AES and On-Line UV-vis Detection. Rapid Commun. Mass Spectrom. 1999, 13, 323-330.

24. Null, A. P.; Hannis, J. C.; Muddiman, D. C. Preparation of Single-Stranded PCR Products for Electrospray Ionization Mass Spectrometry Using the DNA Repair Enzyme Lambda Exonuclease. Analyst (Special Issue: Biological Mass Spectrometry) 2000, 125, 619-625.

25. Hannis, J. C.; Muddiman, D. C.; Null, A. P. Advances in Nucleic Acid and Protein Analyses, Manipulation, and Sequencing; SPIE-Bios Meeting, San Jose, CA, January 2000; pp $36-47$.

26. Hannis, J. C.; Muddiman, D. C. A Dual Electrospray Ionization Source Combined with Hexapole Accumulation to Achieve High Mass Accuracy of Bioploymers in FTICR Mass Spectrometry. J. Am. Soc. Mass Spectrom. 2000, 11, 876-883.

27. Hannis, J. C.; Muddiman, D. C. Detection of Double-Stranded PCR Amplicons at the Attomole Level Electrosprayed from Low Nanomolar Solutions Using FT-ICR Mass Spectrometry. Fresenius J. Anal. Chem. 2001, 369, 246-251.

28. Null, A. P.; Hannis, J. C.; Muddiman, D. C. Genotyping Simple and Compound Short Tandem Repeat Loci Using Electrospray Ionization Fourier Transform Ion Cyclotron Resonance Mass Spectrometry . Anal. Chem. 2001, 73(18), 4514-4521.

29. Sambrook, J.; Fritsch, E. F.; Maniatis, T. Molecular Cloning; 2nd ed. Cold Spring Harbor Laboratory: Plainview, 1989, p E.10.

30. Crouse, J.; Amorese, D. Ethanol Precipitation: Ammonium Acetate as an Alternative to Sodium Acetate. Focus 1987, 9, 3.

31. Qiagen (Valencia, CA) Isopropanol Precipitation of DNA. Qiagen News 1999, 21-23.

32. Muddiman, D. C.; Null, A. P.; Hannis, J. C. Precise Mass Measurement of a Double-Stranded 500 Base-Pair (309 kDa) 
Polymerase Chain Reaction Product by Negative Ion Electrospray Ionization Fourier Transform Ion Cyclotron Resonance Mass Spectrometry. Rapid Commun. Mass Spectrom. 1999, 13, 1201-1204.

33. Hannis, J. C.; Muddiman, D. C. Nanoelectrospray Mass Spectrometry Using Non-Metalized, Tapered $(50-10 \mu \mathrm{m})$ FusedSilica Capillaries. Rapid Commun. Mass Spectrom. 1998, 12, 443-448.

34. Chowdhury, S. K.; Katta, V.; Chait, B. T. An ElectrosprayIonization Mass Spectrometer with New Features. Rapid Commun. Mass Spectrom. 1990, 4, 81-87.
35. Flora, J. W.; Hannis, J. C.; Muddiman, D. C. High-Mass Accuracy of Product Ions Produced by SORI-CID Using a Dual Electrospray Ionization Source Coupled with FTICR Mass Spectrometry. Anal. Chem. 2001, 73, 1247-1251.

36. Greig, M.; Griffey, R. H. Utility of Organic Bases for Improved Electrospray Mass Spectrometry of Oligonucleotides. Rapid Commun. Mass Spectrom. 1995, 9, 97-102.

37. Muddiman, D. C.; Cheng, X. H.; Udseth, H. R.; Smith, R. D. Charge-State Reduction with Improved Signal Intensity of Oligonucleotides in Electrospray Ionization Mass Spectrometry. J. Am. Soc. Mass Spectrom. 1996, 7, 697-706. 